\title{
What factors have impact on glucocorticoid replacement in adrenal insufficiency: a real-life study
}

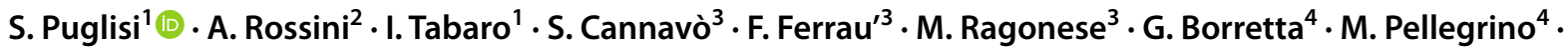

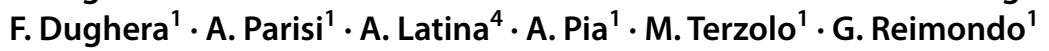

Received: 16 June 2020 / Accepted: 2 August 2020 / Published online: 10 August 2020

(c) The Author(s) 2020

\begin{abstract}
Purpose The impact of patient's characteristics on glucocorticoid (GC) replacement therapy in adrenal insufficiency (AI) is poorly evaluated. Aims of this study were to assess the influence of sex and body weight on GC dosing and to describe the choice of GC in AI of different etiologies.

Methods We retrospectively evaluated hydrocortisone (HC) equivalent total daily dose (HC-TDD) and per-kg-daily dose (HC-KDD) in 203 patients (104 primary AI [pAI], 99 secondary AI [sAI]) followed up for $\geq 12$ months. They were treated with HC, modified-release HC (MRHC) or cortisone acetate (CA) and fludrocortisone acetate (FCA) in pAI.

Results At baseline, CA was preferred both in pAI and sAI; at last visit, MRHC was most used in pAI (49\%) and CA in sAI (73.7\%). Comparing the last visit with baseline, in pAI, HC-TDD and HC-KDD were significantly lower $(p=0.04$ and $p=0.006$, respectively), while FCA doses increased during follow-up $(p=0.02)$. The reduction of HC-TDD and HC-KDD was particularly relevant for pAI women ( $p=0.04$ and $p=0.002$, respectively). In sAI patients, no change of HC-KDD and HC-TDD was observed, and we found a correlation between weight and HC-TDD in males $(r 0.35, p=0.02)$.

Conclusions Our real-life study demonstrated the influence of etiology of AI on the type of GC used, a weight-based tailoring in sAI, a likely overdosage of GC treatment in pAI women at the start of treatment and the possibility to successfully increase FCA avoiding GC over-treatment. These observations could inform the usual clinical practice.
\end{abstract}

Keywords Hypoadrenalism · Addison $\cdot$ Hydrocortisone $\cdot$ Fludrocortisone $\cdot$ Management

\section{Introduction}

Adrenal insufficiency (AI) is a rare but potentially lifethreatening condition, characterized by impaired cortisol secretion due to a primary loss of function of the adrenal

S. Puglisi and A. Rossini should be considered joint first authors.

S. Puglisi

sorayapuglisi@yahoo.it

1 Internal Medicine, Department of Clinical and Biological Sciences, University of Turin, Regione Gonzole 10, 10043 Orbassano, Italy

2 Endocrinology and Diabetes Unit, ASST Papa Giovanni XXIII, Bergamo, Italy

3 Department of Human Pathology 'G.Barresi', University of Messina, Messina, Italy

4 Division of Endocrinology, AO S. Croce E Carle, Cuneo, Italy cortex [pAI] or secondary to a dysfunction of the hypothalamic-pituitary-adrenal axis [sAI]. The prevalence of pAI is lower than sAI (93-140 per million vs $150-280$ per million, respectively) [1]. Both pAI and sAI patients need life-long treatment with glucocorticoids (GC) that, only in pAI, should be coupled with a mineralocorticoid analogue. Unfortunately, the long-term management of therapy is tricky, due to several issues.

Primarily, the physiological pattern of cortisol secretion is difficult to mirror using the conventional oral replacement therapy regimens [immediate-release hydrocortisone (HC), cortisone acetate (CA) or prednisolone] [2]. For this reason, a new formulation of once daily HC, defined as modifiedrelease hydrocortisone (MRHC), has been recently introduced [3, 4]. MRHC use was associated with better quality of life and improved metabolic parameters compared with conventional GC regimens [5, 6]. However, a reliable biomarker to assess the adequacy of GC treatment in AI has not yet been identified and the dosage adjustments, whatever GC 
therapy is used, are guided only by the evaluation of clinical parameters and the personal judgment of the physician.

It is known that also patients on optimum replacement regimes are affected by more than a twofold increase in the standardized mortality ratio [7-10]. The reason of increased mortality is still unclear, but it is likely that underestimated conditions of under- and over-treatment could play a role. Indeed, chronic exposure to glucocorticoid over-replacement is associated with impaired glucose metabolism, central adiposity, higher cardiovascular risk and bone complications $[11,12]$, while an under-treatment causes adrenal crises, which can be potentially fatal $[13,14]$.

Although GC replacement is mainly based on clinical practice, the impact of patient's characteristics on daily GC requirement is poorly evaluated. There are few studies assessing the role of body weight on GC therapy. In 2004, Mah et al. reported that weight was the most important predictor of $\mathrm{HC}$ clearance and recommended weight-adjusted $\mathrm{HC}$ dosing [15]. More recently, Debono et al. stated that a weight-related thrice-daily dosing regimen is the best approach to tailoring hydrocortisone dose to meet patient needs and reproducing the cortisol circadian rhythm [16]. Few studies investigated sex-related differences in GC replacement, and reported conflicting results [17-19]. Moreover, there is a paucity of data regarding the choice of GC treatments for $\mathrm{AI}$ in real-world clinical practice.

Therefore, the primary aim of this study was to assess the influence of sex and body weight on dosing GC in patients with AI of different etiology and the secondary objective was to provide a survey of the use of different GC formulations (MRHC or other standard replacement therapy) in pAI and sAI.

\section{Patients and methods}

\section{Patients}

We retrospectively analyzed 203 consecutive patients with an established diagnosis of adrenal insufficiency, who were referred to three tertiary centers (San Luigi Gonzaga Hospital-University of Turin; Santa Croce e Carle Hospital of Cuneo; Gaetano Martino Hospital-University of Messina), between January 1995 and December 2018. Inclusion criteria were age at diagnosis $\geq 18$ years; follow-up at the same center $\geq 12$ months; stable glucocorticoid replacement for at least 6 months prior to the last visit. Patients treated with long-term exogenous glucocorticoids were excluded.

\section{Methods}

Medical records were reviewed to obtain clinical information and to validate the diagnosis of AI, based on low basal serum cortisol $(<3 \mu \mathrm{g} / \mathrm{dL})$ coupled with, in case of pAI, plasma levels of adrenocorticotropic hormone (ACTH) exceeding $100 \mathrm{pg} / \mathrm{ml}$ or abnormal response to the standard dose ACTH stimulation test (peak serum cortisol $<18 \mu \mathrm{g} /$ dL) $[20,21]$.

The following data were collected from medical charts: date of birth, sex, etiology of AI, date of first visit (baseline), date of last visit and date of death. We retrieved, both at baseline and at last visit: age, weight, body mass index (BMI), waist, biochemical values (glycemia, glycated hemoglobin [HbA1c], total cholesterol, HDL cholesterol, triglycerides, electrolytes), cardiovascular or metabolic comorbidities (arterial hypertension, diabetes mellitus, dyslipidemia, cardiovascular events), and occurrence of adrenal crises. According to Hahner et al. [14], an adrenal crisis was defined as a worsening of the general condition with signs and symptoms of glucocorticoid and/or mineralocorticoid deficiency with at least two of the following conditions: (a) hypotension (systolic blood pressure $<100 \mathrm{mmHg}$ ), (b) nausea or vomiting, (c) severe fatigue, (d) documented hyponatremia, hyperkalemia, or hypoglycemia, and sub-sequent parenteral glucocorticoid administration. Adrenal crises that occurred before the diagnosis and start of replacement therapy were excluded from analysis. Presence of associated endocrine deficiencies [hypothyroidism, growth hormone $(\mathrm{GH})$ deficiency, hypogonadism] and any replacement therapy were reported.

We registered the type of GC replacement therapy (CA, $\mathrm{HC}$, MRHC; none of the patients were treated with prednisolone in our population), the frequency of administration and total daily dose both at baseline and at last visit. In pAI, total daily dose of mineralocorticoid (fludrocortisone acetate, FCA) replacement therapy was also reported. Cortisone acetate doses were calculated as HC-equivalent doses (mg cortisone acetate $/ 1.25=\mathrm{mg}$ hydrocortisone) and we evaluated the HC total daily dose (HC-TDD) and per-kg-daily dose (HC-KDD).

The study was approved by the ethical committees of San Luigi Gonzaga Hospital-University of Turin, Santa Croce e Carle Hospital of Cuneo, Gaetano Martino Hospital-University of Messina, and it was conducted in accordance with the Declaration of Helsinki. The need to obtain informed consent from the study participants was waived due to the study's retrospective and observational nature.

\section{Statistical analysis}

Categorical data are presented as counts and percentages. Continuous data are presented as means and standard deviations (SD). Differences in categorical variables were analyzed by means of the Chi-square test or Fisher test as appropriate, while differences in continuous variables by the Mann-Whitney $U$ test. Correlation analyses were 
determined by calculating the Spearman's $R$ coefficient. All reported $P$ values are two sided. $P$ values less than 0.05 were considered as statistically significant. The statistical analyses were performed with SPSS Statistics-version 25.0 IBM CORPC.

\section{Results}

We analyzed 203 patients (118 females, F, 85 males, M) with a median age of 47 (range 18-88) years. Median follow-up was 75 (range 12-264) months. According to etiology of AI, we considered two different groups: 104 pAI patients $(65 \mathrm{~F}$, $39 \mathrm{M}$ ) and 99 sAI patients (53 F, $46 \mathrm{M})$.

At baseline, we did not observe any difference in clinical characteristics and comorbidities between pAI and sAI (Table 1), except for higher BMI and diastolic blood pressure levels in sAI and higher rate of adrenal crises in pAI. HC-TDD and HC-KDD were higher in pAI than in sAI.

At baseline, although either in pAI or in sAI CA was the preferred starting treatment, the use of $\mathrm{HC}$ was greater

Table 1 Baseline features of pAI and sAI

\begin{tabular}{|c|c|c|c|}
\hline Characteristics & $\begin{array}{l}\text { pAI } \\
(n=104)\end{array}$ & sAI $(n=99)$ & $p$ \\
\hline $\begin{array}{l}\text { Gender } N(\%) \\
\text { Male } \\
\text { Female }\end{array}$ & $\begin{array}{l}39(37.5 \%) \\
65(62.5 \%)\end{array}$ & $\begin{array}{l}46(46.5 \%) \\
53(53.5 \%)\end{array}$ & NS \\
\hline $\begin{array}{l}\text { Age at diagnosis (year) } \\
\text { Mean } \pm \text { SD }\end{array}$ & $46.5 \pm 15.4$ & $50.0 \pm 17.2$ & \\
\hline $\begin{array}{l}\text { Weight }(\mathrm{kg}) \\
\text { Mean } \pm \text { SD }\end{array}$ & $69.4 \pm 16.5$ & $74.1 \pm 18.1$ & NS \\
\hline $\begin{array}{l}\text { BMI }\left(\mathrm{kg} / \mathrm{m}^{2}\right) \\
\text { Mean } \pm \text { SD }\end{array}$ & $25.3 \pm 5.4$ & $26.9 \pm 5.7$ & 0.04 \\
\hline $\begin{array}{l}\text { Waist }(\mathrm{cm}) \\
\text { Mean } \pm \text { SD }\end{array}$ & $93.9 \pm 17.1$ & $96.8 \pm 13.2$ & NS \\
\hline $\begin{array}{l}\text { Systolic blood pressure }(\mathrm{mmHg}) \\
\text { Mean } \pm \mathrm{SD}\end{array}$ & $119 \pm 17$ & $123 \pm 17$ & NS \\
\hline $\begin{array}{l}\text { Diastolic blood pressure } \\
(\mathrm{mmHg}) \\
\text { Mean } \pm \mathrm{SD}\end{array}$ & $75 \pm 10$ & $79 \pm 11$ & 0.007 \\
\hline Hypertension $N(\%)$ & $21(20.2 \%)$ & $31(31.3 \%)$ & NS \\
\hline Diabetes mellitus $N(\%)$ & $16(15.4 \%)$ & $11(11.1 \%)$ & NS \\
\hline Dyslipidemia $N(\%)$ & $75(72.1 \%)$ & $69(69.6 \%)$ & NS \\
\hline Cardiovascular events $N(\%)$ & $9(8.6 \%)$ & $7(7.1 \%)$ & NS \\
\hline Adrenal crisis $N(\%)$ & $15(14.4 \%)$ & $3(3.0 \%)$ & 0.009 \\
\hline $\begin{array}{l}\text { HC-TDD (mg/day) } \\
\text { Mean } \pm \text { SD }\end{array}$ & $25.8 \pm 7.4$ & $21.1 \pm 8.5$ & $<0.001$ \\
\hline $\begin{array}{l}\mathrm{HC}-\mathrm{KDD}(\mathrm{mg} / \mathrm{kg} / \text { day }) \\
\text { Mean } \pm \mathrm{SD}\end{array}$ & $0.44 \pm 0.17$ & $0.33 \pm 0.14$ & $<0.001$ \\
\hline
\end{tabular}

Bold values indicate statistically significant values

$S D$ standard deviation, $B M I$ body mass index, $H C$ - $T D D$ hydrocortisone total daily dose, $H C$ - KDD hydrocortisone per-kg-daily dose in pAI than in sAI $(p<0.001)$ (Fig. 1a). Ten patients with pAI started at baseline MRHC treatment. During followup, an additional subgroup of 53 patients (43 pAI and $10 \mathrm{sAI})$ has been switched to MRHC therapy. Three of them ( $2 \mathrm{pAI}$ and $1 \mathrm{sAI})$ discontinued the new therapy after few months due to the limited clinical improvement and restarted the previous treatment with $\mathrm{CA}$ or $\mathrm{HC}$. At last visit, the rate of patients in MRHC was higher in pAI than in sAI $(p<0.001)$ and CA was still preferred in sAI (Fig. 1b).

At last visit, we found higher weight, BMI, waist, systolic and diastolic blood pressure levels in sAI (Table 2), without difference in other comorbidities or occurrence of adrenal crises. HC-TDD and HC-KDD were still higher in pAI than in sAI.

Comparing the last visit with baseline, in pAI group weight and BMI were stable, but HC-TDD and HC-KDD were significantly lower $(23.8 \pm 6.7$ vs $25.8 \pm 7.4 \mathrm{mg} /$ day, $p=0.04$ and $0.38 \pm 0.14$ vs $0.44 \pm 0.17 \mathrm{mg} / \mathrm{kg} /$ day, $p=0.006$, respectively), while FCA doses increased during follow-up $(0.06 \pm 0.03$ vs $0.07 \pm 0.03 \mathrm{mg} / \mathrm{kg} /$ day, $p=0.02)$.

In sAI patients, weight, BMI, HC-KDD and HC-TDD were not different between baseline and last visit.

A

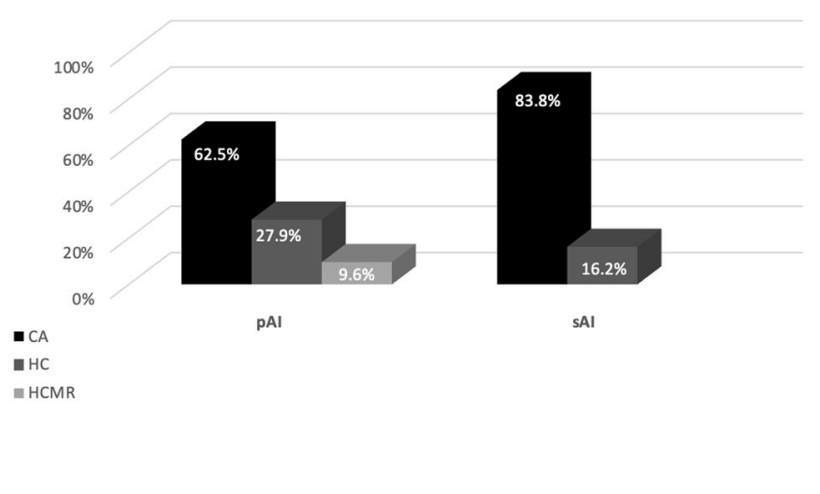

B

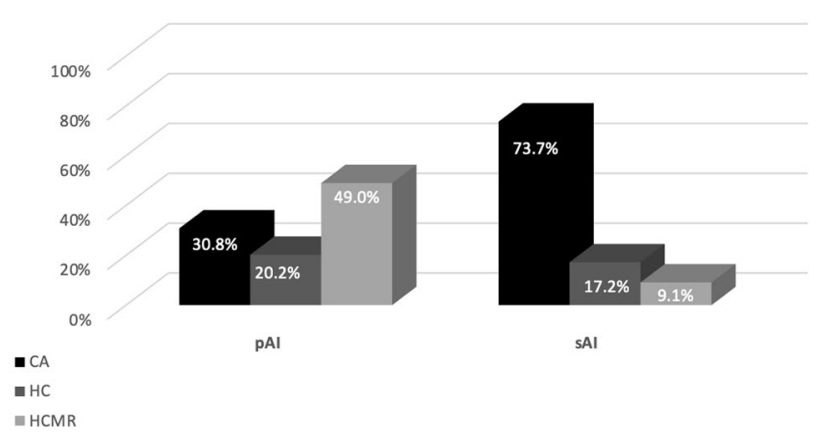

Fig. 1 Comparison of glucocorticoid therapies between pAI and sAI groups, at baseline (a) at last visit (b) 
Table 2 Characteristics of pAI and sAI at last visit

\begin{tabular}{|c|c|c|c|}
\hline Characteristics & $\mathrm{pAI}(n=104)$ & sAI $(n=99)$ & $p$ \\
\hline $\begin{array}{l}\text { Gender } N(\%) \\
\text { Male } \\
\text { Female }\end{array}$ & $\begin{array}{l}39(37.5 \%) \\
65(62.5 \%)\end{array}$ & $\begin{array}{l}46(46.5 \%) \\
53(53.5 \%)\end{array}$ & NS \\
\hline $\begin{array}{l}\text { Age at diagnosis (year) } \\
\text { Mean } \pm \text { SD }\end{array}$ & $52.7 \pm 15.6$ & $56.1 \pm 17.1$ & NS \\
\hline $\begin{array}{l}\text { Weight }(\mathrm{kg}) \\
\text { Mean } \pm \text { SD }\end{array}$ & $69.3 \pm 14.9$ & $74.7 \pm 18.2$ & 0.02 \\
\hline $\begin{array}{l}\text { BMI }\left(\mathrm{kg} / \mathrm{m}^{2}\right) \\
\text { Mean } \pm \mathrm{SD}\end{array}$ & $25.3 \pm 5.0$ & $27.2 \pm 6.0$ & 0.02 \\
\hline $\begin{array}{l}\text { Waist }(\mathrm{cm}) \\
\text { Mean } \pm \text { SD }\end{array}$ & $91.0 \pm 13.0$ & $98.7 \pm 11.0$ & $<0.001$ \\
\hline $\begin{array}{l}\text { Systolic blood pressure } \\
(\mathrm{mmHg}) \\
\text { Mean } \pm \text { SD }\end{array}$ & $121 \pm 15$ & $126 \pm 18$ & $\mathbf{0 . 0 3}$ \\
\hline $\begin{array}{l}\text { Diastolic blood pressure } \\
(\mathrm{mmHg}) \\
\text { Mean } \pm \mathrm{SD}\end{array}$ & $75 \pm 10$ & $78 \pm 11$ & 0.04 \\
\hline Hypertension $N(\%)$ & $28(26.9 \%)$ & $39(39.4 \%)$ & NS \\
\hline Diabetes mellitus $N(\%)$ & $15(14.4 \%)$ & $13(13.1 \%)$ & NS \\
\hline Dyslipidemia $N(\%)$ & $57(54.8 \%)$ & $61(61.6 \%)$ & NS \\
\hline Cardiovascular events $N(\%)$ & $5(4.8 \%)$ & $5(5.1 \%)$ & NS \\
\hline Adrenal crisis $N(\%)$ & $11(10.6 \%)$ & $4(4.0 \%)$ & NS \\
\hline $\begin{array}{l}\text { HC-TDD (mg/day) } \\
\text { Mean } \pm \text { SD }\end{array}$ & $23.8 \pm 6.7$ & $20.7 \pm 7.9$ & 0.003 \\
\hline $\begin{array}{l}\mathrm{HC}-\mathrm{KDD}(\mathrm{mg} / \mathrm{kg} / \text { day }) \\
\text { Mean } \pm \mathrm{SD}\end{array}$ & $0.38 \pm 0.14$ & $0.32 \pm 0.13$ & 0.002 \\
\hline
\end{tabular}

Bold values indicate statistically significant values

$S D$ standard deviation, $B M I$ body mass index, $H C-T D D$ hydrocortisone total daily dose, $H C-K D D$ hydrocortisone per-kg-daily dose

\section{Sex-related differences}

At baseline, either in patients with pAI or sAI we did not observe any sex-related differences in clinical characteristics, biochemical value, comorbidities and occurrence of adrenal crises, except for higher weight in men, higher waist in men only in SAI and higher systolic blood pressure levels only in pAI men compared to pAI women (Tables 3, 4). While in SAI HC-KDD and HC-TDD were not significantly different between men and female (Table 4), in pAI $\mathrm{HC}-\mathrm{KDD}$ was higher in $\mathrm{F}$ than in $\mathrm{M}$ (Table 3). Interestingly, only in $\mathrm{M}$ with sAI we have observed a correlation between weight and HC-TDD $(r 0.57, p<0.001)$. We have not observed any significant difference between $\mathrm{M}$ and $\mathrm{F}$ for the occurrence of hypogonadism, hypothyroidism or GH deficiency (Table 4).

At baseline, doses of FCA were similar between $\mathrm{M}$ and $\mathrm{F}$ and in both groups, weight and BMI were not correlated with FCA dose.

Comparing the last visit with baseline, in F with pAI weight was stable, but HC-TDD was significantly reduced $(25.8 \pm 8.0$ vs $23.2 \pm 6.3 \mathrm{mg} / \mathrm{day}, p=0.04)$, as well as
Table 3 Baseline features of pAI, classified according to sex

\begin{tabular}{llll}
\hline Characteristics & $\mathrm{F}(n=65)$ & $\mathrm{M}(n=39)$ & $p$ \\
\hline $\begin{array}{l}\text { Age at diagnosis (year) } \\
\text { Mean } \pm \text { SD }\end{array}$ & $46.7 \pm 14.9$ & $46.4 \pm 16.1$ & $\mathrm{NS}$ \\
Weight $(\mathrm{kg})$ & $66.2 \pm 17.5$ & $74.8 \pm 13.2$ & $\mathbf{0 . 0 1}$ \\
Mean $\pm \mathrm{SD}$ & & & \\
BMI $\left(\mathrm{kg} / \mathrm{m}^{2}\right)$ & $25.4 \pm 6.2$ & $25.1 \pm 3.8$ & $\mathrm{NS}$ \\
Mean $\pm \mathrm{SD}$ & & & \\
Waist $(\mathrm{cm})$ & $93.7 \pm 19.4$ & $94.0 \pm 11.2$ & $\mathrm{NS}$ \\
Mean \pm SD & & & \\
Systolic blood pressure (mmHg) & $116 \pm 18$ & $125 \pm 15$ & $\mathbf{0 . 0 1}$ \\
Mean \pm SD & & & \\
Diastolic blood pressure (mmHg) & $74.0 \pm 10.7$ & $77.0 \pm 7.9$ & $\mathrm{NS}$ \\
Mean \pm SD & & & \\
Hypertension $N(\%)$ & $12(18.4 \%)$ & $9(23.1 \%)$ & NS \\
Diabetes mellitus $N(\%)$ & $9(13.8 \%)$ & $7(17.9 \%)$ & NS \\
Dyslipidemia $N(\%)$ & $46(70.7 \%)$ & $29(74.3 \%)$ & NS \\
Cardiovascular events $N(\%)$ & $5(7.7 \%)$ & $4(10.2 \%)$ & NS \\
Adrenal crisis $N(\%)$ & $9(13.8 \%)$ & $6(15.4 \%)$ & NS \\
HC-TDD (mg/day) & $25.8 \pm 8.0$ & $25.8 \pm 6.2$ & NS \\
Mean \pm SD & & & \\
HC-KDD (mg/kg/day) & $0.47 \pm 0.19$ & $0.38 \pm 0.17$ & $\mathbf{0 . 0 2}$ \\
Mean \pm SD & & & \\
\hline
\end{tabular}

Bold values indicate statistically significant values

$B M I$ body mass index, $H C$-TDD hydrocortisone total daily dose, $H C$ $K D D$ hydrocortisone per-kg-daily dose

$\mathrm{HC}-\mathrm{KDD}(0.47 \pm 0.19$ vs $0.38 \pm 0.14 \mathrm{mg} / \mathrm{kg} / \mathrm{day}, p=0.002)$. Doses of FCA were similar to baseline.

In $\mathrm{M}$ with pAI, BMI, HC-KDD and HC-TDD were not significantly different between baseline and last visit.

At last visit, HC-KDD, HC-TDD and FCA doses were not significantly different between $\mathrm{M}$ and $\mathrm{F}$ and did not correlate with weight or BMI. Moreover, during the follow-up period, the occurrence of adrenal crises and comorbidities were comparable between groups and not significantly different comparing with baseline.

In patients with sAI at last visit, the weight of female was stable when compared to baseline, but HC-TDD was significantly lower in $\mathrm{F}$ than in $\mathrm{M}(\mathrm{F}, 18.4 \pm 6.9$ vs $\mathrm{M}$, $23.4 \pm 8.1 \mathrm{mg} /$ day, $p=0.001$ ), without any change in HCKDD. In male patients with sAI, BMI, HC-KDD and HCTDD were not different between baseline and last visit. Also at last visit in SAI, we have not observed any significant difference between $\mathrm{M}$ and $\mathrm{F}$ for other pituitary deficiencies and all the patients were on adequate replacement treatment. Moreover, data were comparable with baseline.

At last visit in sAI, although we have not observed any significant differences of HC-TDD and HC-KDD between males and females, only in $\mathrm{M}$ we have demonstrated a correlation between weight and HC-TDD $(r 0.35, p=0.02)$.

Interestingly, only in male patients, BMI and waist circumference were higher in SAI than in PAI either at 
Table 4 Baseline features of sAI, classified according to sex

\begin{tabular}{|c|c|c|c|}
\hline Characteristics & $F(n=53)$ & $M(n=46)$ & $p$ \\
\hline $\begin{array}{l}\text { Age at diagnosis (year) } \\
\text { Mean } \pm \text { SD }\end{array}$ & $49.6 \pm 15.7$ & $50.1 \pm 19.1$ & NS \\
\hline $\begin{array}{l}\text { Weight }(\mathrm{kg}) \\
\text { Mean } \pm \text { SD }\end{array}$ & $67.8 \pm 16.3$ & $81.3 \pm 17.6$ & $<0.001$ \\
\hline $\begin{array}{l}\text { BMI }\left(\mathrm{kg} / \mathrm{m}^{2}\right) \\
\text { Mean } \pm \text { SD }\end{array}$ & $26.5 \pm 6.3$ & $27.6 \pm 4.9$ & NS \\
\hline $\begin{array}{l}\text { Waist }(\mathrm{cm}) \\
\text { Mean } \pm \text { SD }\end{array}$ & $92.8 \pm 14.8$ & $100.2 \pm 11.0$ & 0.007 \\
\hline $\begin{array}{l}\text { Systolic blood pressure } \\
(\mathrm{mmHg}) \\
\text { Mean } \pm \text { SD }\end{array}$ & $121.8 \pm 19.3$ & $124.7 \pm 19.3$ & NS \\
\hline $\begin{array}{l}\text { Diastolic blood pressure } \\
(\mathrm{mmHg}) \\
\text { Mean } \pm \text { SD }\end{array}$ & $78.9 \pm 10.8$ & $78.5 \pm 11.6$ & NS \\
\hline Hypertension $N(\%)$ & $15(28.3 \%)$ & $16(34.8 \%)$ & NS \\
\hline Diabetes mellitus $N(\%)$ & $5(9.4 \%)$ & $6(13.0 \%)$ & NS \\
\hline Dyslipidemia $N(\%)$ & $38(71.7 \%)$ & $31(67.4 \%)$ & NS \\
\hline Cardiovascular events $N(\%)$ & $3(5.6 \%)$ & $4(8.7 \%)$ & NS \\
\hline Adrenal crisis $N(\%)$ & $1(1.9 \%)$ & $2(4.6 \%)$ & NS \\
\hline Hypogonadism $N(\%)$ & $39(73.6 \%)$ & $36(78.3 \%)$ & NS \\
\hline Hypothyroidism $N(\%)$ & $42(79.2 \%)$ & $39(84.8 \%)$ & NS \\
\hline GH deficiency $N(\%)$ & $26(49.1 \%)$ & $24(52.2 \%)$ & NS \\
\hline HC-TDD (mg/day) & & & \\
\hline $\begin{array}{l}\text { Mean } \pm \text { SD } \\
\text { HC-KDD (mg/kg/day) }\end{array}$ & $19.8 \pm 8.3$ & $22.6 \pm 8.7$ & NS \\
\hline Mean \pm SD & $0.35 \pm 0.16$ & $0.31 \pm 0.11$ & NS \\
\hline
\end{tabular}

Bold values indicate statistically significant values

$B M I$ body mass index, $H C$ - $T D D$ hydrocortisone total daily dose, $H C$ $K D D$ hydrocortisone per-kg-daily dose

baseline (waist $100.2 \pm 11.0$ vs $94.0 \pm 11.2 \mathrm{~cm}, p=0.01$, BMI $27.6 \pm 4.9$ vs $\left.25.1 \pm 3.8 \mathrm{~kg} / \mathrm{m}^{2}, p=0.01\right)$ or at the last follow-up (waist $102.2 \pm 10.7$ vs $92.7 \pm 10.5 \mathrm{~cm}, p=0.001$, BMI $27.3 \pm 5.2$ vs $24.9 \pm 3.4 \mathrm{~kg} / \mathrm{m}^{2}, p=0.001$ ), while these parameters were comparable for female patients.

At last visit, comorbidities and occurrence of adrenal crises were comparable between groups and not significantly different comparing with baseline.

\section{Discussion}

The replacement therapy of AI in clinical practice is characterized by a significant heterogeneity in type and dosage of the prescribed GCs [22]. To our knowledge, few works so far investigated the impact of patients' characteristics on this heterogeneity. In our study, we evaluated how gender, weight, and AI etiology influenced the management of AI in three referral centers in Italy.

In our AI patients, CA was the preferred therapy. This is in contrast with previous published data reporting that in most countries $\mathrm{HC}$ is the drug of choice for adrenal insufficiency $[17,18,23]$. CA is biologically inactive, requiring conversion to cortisol by $11 \mathrm{bHSD} 1$, and this may lead to a slight delay in achieving the peak of serum cortisol levels [24]. For this reason, HC is often preferred, although at present there are no data showing its superiority over CA [25]. On the other hand, it has been reported that CA is widely prescribed in Italy given that $\mathrm{HC}$ is not readily available and needs specific prescription by an endocrinologist $[26,27]$. Therefore, the higher proportion of patient being treated with CA in our cohort reflects common clinical practice of our country, due to the prompt availability of CA.

In our study population, CA was more frequently prescribed to patients with secondary ( $\mathrm{sAI}$ ) than primary (pAI) adrenal insufficiency. To our knowledge, this is an unreported finding since most studies show that the etiology of AI does not influence the choice of treatment $[18,23]$. Secondary AI is usually associated with other pituitary defects known to interfere with the conversion of CA to cortisol, particularly growth hormone (GH) deficiency [28]; thus, CA seems unsuitable in this setting. Despite that, some data suggest that CA may be a better option than $\mathrm{HC}$ in patients with sAI. Swords et al. [29] reported a lower 11 bHSD activity when hypopituitary patients were taking CA compared to those taking $\mathrm{HC}$, thus leading to a more physiological tissue exposure to glucocorticoid. Moreover, Filipsson et al. [30] observed that sAI patients receiving $\mathrm{HC}$ displayed a higher risk of developing an adverse metabolic profile than those using CA. The prompt availability and these data should support the prevalent use of CA.

MRHC is a novel HC formulation designed to more closely mimic the circadian rhythm of cortisol secretion [3]. Several studies reported advantages of MRHC over the conventional GC formulations with regard to metabolic outcomes, QoL and compliance [4, 31, 32]. In our cohort, MRHC was rarely considered as starting treatment, but its use significantly increased over time and one third of patients were taking MRHC at the end of the study. The shift to MRHC was generally well tolerated except for three patients that preferred the previous treatment. The observation that patients with pAI were more frequently treated with MRHC than those with sAI both at baseline and at the end of the study is not completely unexpected since MRHC has been extensively studied only in pAI [33] while data in sAI are less conclusive. Mongioì et al. have recently reported a less beneficial effect on metabolic profile in sAI patients treated with MRHC [34], although also in these patients was reported a maintained improvement in the clinical condition and subjective well-being. Moreover, commercially available MRHC preparations are not always easy to tailor for the majority of sAI patients that require low-intermediate doses and costs are much higher with that formulation [27]. 
At baseline, patients with pAI were treated with higher doses of glucocorticoid than those with sAI, and this was confirmed at the end of the study despite a significant reduction of HC dose took place in pAI. This finding is in agreement with previous data showing that patients with sAI need lower replacement doses since they could maintain a residual cortisol secretion [35]. Patients with pAI are also more prone to receive supraphysiological doses of $\mathrm{HC}$, and this is likely explained by the fear of adrenal crises. We cannot draw any conclusion in this regard since our study was not aimed at evaluating comorbidities. In our cohort, patients with sAI displayed higher BMI and blood pressure values than those with pAI, but sAI is more often associated to comorbidities that may impact the metabolic profile of the patients.

Weight is an important variable determining glucocorticoid clearance, and the use of weight-based regimens instead of fixed doses of $\mathrm{HC}$ has been advocated for the treatment of $\mathrm{AI}[15,16]$. In our patients, the replacement doses of GC correlated with weight in male patients with sAI but not in those with pAI. This could be due to a different fat distribution between the two groups observed at last visit and also at baseline, with a prevalence of central obesity in sAI male patients without any difference for female patients. It has been demonstrated that in obese subjects cortisol clearance show a correlation with intra-abdominal fat [36]; therefore, it is possible that in sAI patients, who are more frequently affected by overweight and obesity (due to concomitant pituitary hormones deficiency), weight could likely influence the dose of GC. Our data seem to demonstrate that this effect is more evident in males than in females. In sAI, glucocorticoid replacement is usually associated with therapies interfering with cortisol metabolism [27], and this was confirmed in our cohort since most patients with sAI were treated for other hormonal deficiencies. However, we have not observed a possible influence either of the hormonal deficiencies' prevalence or the replacement treatment on the effect of different glucocorticoid replacement therapy on males and females.

So far, few studies evaluated the impact of gender on the replacement therapy of hypocortisolism. Iqbal et al. analyzed a population of 2648 AI patients from UK, showing that females were more often treated with long-acting glucocorticoid than males, but they did not report data about replacement doses [18]. Dalin et al. did not find differences between sexes in the body surface-adjusted HC dose in a population of more than 600 Swedish patients with autoimmune Addison disease [17], while Skov et al., in a similar cohort, reported a slightly higher total HC dose in males [19].

In our patients with pAI, females received at baseline a glucocorticoid dose adjusted for body weight significantly higher than males. This difference was no longer present at the end of the observational period, due to a significant reduction of the replacement doses in the female subgroup. Males and females with sAI were treated with a similar weight-adjusted glucocorticoid dose both at baseline and at the end of the study. Gender does not affect the clearance of hydrocortisone [15] and females display slightly lower serum cortisol levels compared to males [37]. Furthermore, Skov et al. recently reported that women treated with high glucocorticoid replacement doses were more prone to develop cardiovascular events than men [19]. Thus, the fact that in our study females with pAI were treated with higher GC doses compared to males seems mainly related to the use of standard replacement regimens in both sexes. Since males have a significantly higher weight than females, the use of comparable total glucocorticoid doses at baseline resulted in a possible over-replacement in females. By now, it became clear that the normal daily cortisol secretion is lower than once estimated [38] and several data emerged regarding the detrimental consequences of glucocorticoid over-replacement $[30,39]$, leading to a reduction in glucocorticoid doses for treatment of hypocortisolism [20,21]. The significant reduction of glucocorticoid dose observed in our subgroup of females with pAI at the end of the study should be also in part explained by the introduction of the fixed doses of the MRHC treatment that induces to reconsider the total daily doses usually administered.

The majority of patients with pAI require mineralocorticoid replacement with FCA, even if some are well controlled with $\mathrm{HC}$ alone, with variables percentages in the different series $[17,19,26,40]$. In our cohort, all patients with pAI were treated with FCA according to guidelines [20]. Few studies so far have described the characteristics of mineralocorticoid replacement in patients with AI [41]. Interestingly, Dalin et al. [17] reported a similar HC dose in patients with pAI irrespective of whether they were treated with FCA or not. Our data seem to diverge from this observation since in our population of patients with pAI the decrease in $\mathrm{HC}$ dose was paralleled by a significant increase in FCA dose. $\mathrm{HC}$ possess mineralocorticoid activity and $\mathrm{HC}$ over-treatment may offset mineralocorticoid replacement [42]. It is thus likely that the relatively high $\mathrm{HC}$ dose given to our pAI patients at baseline limited the need for FCA. The reduction of $\mathrm{HC}$ dose during follow-up seems to require a parallel increase of FCA to obtain adequate compensation.

The limitation of our study relates to its retrospective nature that may underestimate morbidity. However, the reduction of the administered $\mathrm{HC}$ doses does not seem to be accompanied by an increased frequency of adrenal crises or a worsen health profile. Instead, long-term beneficial effects may be expected on bone and CV events, reducing the number of patients in over-treatment. Moreover, although the GC replacement total daily doses were calculated as HC-equivalent doses, we cannot exclude a possible partial 
influence of the type of therapy, due to the different timing and pharmacokinetics.

In conclusion, our study provides an insight of the management of $\mathrm{AI}$ in the real clinical practice of three referral centers in Italy. We have shown that the diagnosis of primary or secondary AI influences replacement therapy of hypocortisolism either for the preferred drug or its dosage. A greater proportion of patients with sAI were treated with CA, while MRHC was mainly prescribed in patients with pAI. In patients with pAI, weight was not considered at the start of treatment, producing a potential over-replacement in females that was mitigated by the optimization of the therapy during follow-up. Since females with AI may be more exposed to the detrimental effects of glucocorticoids excess, our observation underlines the need of an accurate tailoring of treatment in these patients and the introduction of the MRHC should ease this aim. Moreover, in females pAI patients at diagnosis, we should consider lower starting doses than that usually prescribed in males to avoid potential long-term side effects. Moreover, our data suggest that in patients with pAI, variations in GC replacement should be associated with concomitant adjustments in FCA dosage. This observation may also lead to a review of the usual clinical practice of acting predominantly on HC dosages, while it may be indicated in many patients to also adjust FCA dosages to obtain optimal electrolyte compensation, avoiding $\mathrm{HC}$ over-treatment. On the other hand, patients with SAI were more frequently treated with weight-based glucocorticoid regimens. Our data could support the physician in the decisional process on replacement therapy in different settings increasing the accurate tailoring of treatment in each patient.

Acknowledgments Open access funding provided by Università degli Studi di Torino within the CRUI-CARE Agreement.

Funding Fondi per la Ricerca Locale Università di Torino 2018RILO 2018.

\section{Compliance with ethical standards}

Conflict of interest SP, AR, IT, SC, FF, MR, GB, MP, FD, AP, AL, AA, and MT have nothing to declare. GR is part of the advisory board of Shire-Takeda.

Ethical approval The study was approved by the ethical committees of San Luigi Gonzaga Hospital-University of Turin, Santa Croce e Carle Hospital of Cuneo, Gaetano Martino Hospital-University of Messina, and it was conducted in accordance with the Declaration of Helsinki.

Informed consent The need to obtain informed consent from the study participants was waived due to the study's retrospective and observational nature.

Open Access This article is licensed under a Creative Commons Attribution 4.0 International License, which permits use, sharing, adaptation, distribution and reproduction in any medium or format, as long as you give appropriate credit to the original author(s) and the source, provide a link to the Creative Commons licence, and indicate if changes were made. The images or other third party material in this article are included in the article's Creative Commons licence, unless indicated otherwise in a credit line to the material. If material is not included in the article's Creative Commons licence and your intended use is not permitted by statutory regulation or exceeds the permitted use, you will need to obtain permission directly from the copyright holder. To view a copy of this licence, visit http://creativecommons .org/licenses/by/4.0/.

\section{References}

1. Arlt W, Allolio B (2003) Adrenal insufficiency. Lancet 361:1881-1893

2. Betterle C, Presotto F, Furmaniak J (2019) Epidemiology, pathogenesis, and diagnosis of Addison's disease in adults. J Endocrinol Invest 42:1407-1433

3. Johannsson G, Bergthorsdottir R, Nilsson AG, Lennernas H, Hedner $\mathrm{T}$ et al (2009) Improving glucocorticoid replacement therapy using a novel modified-release hydrocortisone tablet: a pharmacokinetic study. Eur J Endocrinol 161:119-130

4. Johannsson G, Nilsson AG, Bergthorsdottir R, Burman P, Dahlqvist $P$ et al (2012) Improved cortisol exposure-time profile and outcome in patients with adrenal insufficiency: a prospective randomized trial of a novel hydrocortisone dual-release formulation. J Clin Endocrinol Metab 97:473-481

5. Giordano R, Guaraldi F, Marinazzo E, Fumarola F, Rampino A et al (2016) Improvement of anthropometric and metabolic parameters, and quality of life following treatment with dualrelease hydrocortisone in patients with Addison's disease. Endocrine 51:360-368

6. Isidori AM, Venneri MA, Graziadio C, Simeoli C, Fiore D et al (2018) Effect of once-daily, modified-release hydrocortisone versus standard glucocorticoid therapy on metabolism and innate immunity in patients with adrenal insufficiency (DREAM): a single-blind, randomised controlled trial. Lancet Diabetes Endocrinol 6:173-185

7. Bergthorsdottir R, Leonsson-Zachrisson M, Odén A, Johannsson G (2006) Premature mortality in patients with Addison's disease: a population-based study. J Clin Endocrinol Metab 91:4849-4853

8. Bensing S, Brandt L, Tabaroj F, Sjöberg O, Nilsson B et al (2008) Increased death risk and altered cancer incidence pattern in patients with isolated or combined autoimmune primary adrenocortical insufficiency. Clin Endocrinol (Oxf) 69:697-704

9. Chantzichristos D, Persson A, Eliasson B, Miftaraj M, Franzén S et al (2017) Mortality in patients with diabetes mellitus and Addison's disease: a nationwide, matched, observational cohort study. Eur J Endocrinol 176:31-39

10. Quinkler M, Ekman B, Zhang P, Isidori AM, Murray RD et al (2018) Mortality data from the European adrenal insufficiency registry-patient characterization and associations. Clin Endocrinol (Oxf) 89:30-35

11. Mazziotti G, Formenti AM, Frara S, Roca E, Mortini P et al (2017) Management of endocrine disease: risk of overtreatment in patients with adrenal insufficiency: current and emerging aspects. Eur J Endocrinol 177:R231-R248

12. Hardy RS, Zhou H, Seibel MJ, Cooper MS (2018) Glucocorticoids and bone: consequences of endogenous and exogenous excess and replacement therapy. Endocr Rev 39:519-548 
13. Hahner S, Loeffler M, Bleicken B, Drechsler C, Milovanovic D et al (2010) Epidemiology of adrenal crisis in chronic adrenal insufficiency: the need for new prevention strategies. Eur J Endocrinol 162:597-602

14. Hahner S, Spinnler C, Fassnacht M, Burger-Stritt S, Lang K et al (2015) High incidence of adrenal crisis in educated patients with chronic adrenal insufficiency: a prospective study. J Clin Endocrinol Metab 100:407-416

15. Mah PM, Jenkins RC, Rostami-Hodjegan A, Newell-Price J, Doane A et al (2004) Weight-related dosing, timing and monitoring hydrocortisone replacement therapy in patients with adrenal insufficiency. Clin Endocrinol (Oxf) 61:367-375

16. Debono M, Ross RJ (2013) What is the best approach to tailoring hydrocortisone dose to meet patient needs in 2012? Clin Endocrinol (Oxf) 78:659-664

17. Dalin F, Nordling Eriksson G, Dahlqvist P, Hallgren Å, Wahlberg $J$ et al (2017) Clinical and immunological characteristics of autoimmune addison disease: a nationwide swedish multicenter study. J Clin Endocrinol Metab 102:379-389

18. Iqbal K, Halsby K, Murray RD, Carroll PV, Petermann R (2019) Glucocorticoid management of adrenal insufficiency in the United Kingdom: assessment using real-world data. Endocr Connect 8:20-31

19. Skov J, Sundström A, Ludvigsson JF, Kämpe O, Bensing S (2019) Sex-specific risk of cardiovascular disease in autoimmune Addison disease-a population-based cohort study. J Clin Endocrinol Metab 104:2031-2040

20. Bornstein SR, Allolio B, Arlt W, Barthel A, Don-Wauchope A et al (2016) Diagnosis and treatment of primary adrenal insufficiency: an endocrine society clinical practice guideline. J Clin Endocrinol Metab 101:364-389

21. Fleseriu M, Hashim IA, Karavitaki N, Melmed S, Murad MH et al (2016) Hormonal replacement in hypopituitarism in adults: an endocrine society clinical practice guideline. J Clin Endocrinol Metab 101:3888-3921

22. Murray RD, Ekman B, Uddin S, Marelli C, Quinkler M et al (2017) Management of glucocorticoid replacement in adrenal insufficiency shows notable heterogeneity-data from the EUAIR. Clin Endocrinol (Oxf) 86:340-346

23. Forss M, Batcheller G, Skrtic S, Johannsson G (2012) Current practice of glucocorticoid replacement therapy and patient-perceived health outcomes in adrenal insufficiency-a worldwide patient survey. BMC Endocr Disord 12:8

24. Swords FM (2014) Uncertainties in endocrine substitution therapy for central hypocortisolism. Handb Clin Neurol 124:387-396

25. Castinetti F, Guignat L, Bouvattier C, Samara-Boustani D, Reznik Y (2017) Group 4: Replacement therapy for adrenal insufficiency. Ann Endocrinol (Paris) 78:525-534

26. Betterle C, Scarpa R, Garelli S, Morlin L, Lazzarotto F et al (2013) Addison's disease: a survey on 633 patients in Padova. Eur J Endocrinol 169:773-784

27. Isidori AM, Arnaldi G, Boscaro M, Falorni A, Giordano C, et al., (2019) Towards the tailoring of glucocorticoid replacement in adrenal insufficiency: the Italian Society of Endocrinology Expert Opinion. J Endocrinol Invest.

28. Moore JS, Monson JP, Kaltsas G, Putignano P, Wood PJ et al (1999) Modulation of 11 beta-hydroxysteroid dehydrogenase isozymes by growth hormone and insulin-like growth factor: in vivo and in vitro studies. J Clin Endocrinol Metab $84: 4172-4177$
29. Swords FM, Carroll PV, Kisalu J, Wood PJ, Taylor NF et al (2003) The effects of growth hormone deficiency and replacement on glucocorticoid exposure in hypopituitary patients on cortisone acetate and hydrocortisone replacement. Clin Endocrinol (Oxf) 59:613-620

30. Filipsson H, Monson JP, Koltowska-Häggström M, Mattsson A, Johannsson G (2006) The impact of glucocorticoid replacement regimens on metabolic outcome and comorbidity in hypopituitary patients. J Clin Endocrinol Metab 91:3954-3961

31. Quinkler M, Miodini Nilsen R, Zopf K, Ventz M, Øksnes M (2015) Modified-release hydrocortisone decreases BMI and $\mathrm{HbA} 1 \mathrm{c}$ in patients with primary and secondary adrenal insufficiency. Eur J Endocrinol 172:619-626

32. Nilsson AG, Marelli C, Fitts D, Bergthorsdottir R, Burman P et al (2014) Prospective evaluation of long-term safety of dual-release hydrocortisone replacement administered once daily in patients with adrenal insufficiency. Eur J Endocrinol 171:369-377

33. Ceccato F, Scaroni C (2019) Central adrenal insufficiency: open issues regarding diagnosis and glucocorticoid treatment. Clin Chem Lab Med 57:1125-1135

34. Mongioì LM, Condorelli RA, La Vignera S, Calogero AE (2018) Dual-release hydrocortisone treatment: glycometabolic profile and health-related quality of life. Endocr Connect 7:211-219

35. Vulto A, Bergthorsdottir R, van Faassen M, Kema IP, Johannsson $G$ et al (2019) Residual endogenous corticosteroid production in patients with adrenal insufficiency. Clin Endocrinol (Oxf) 91:383-390

36. Lottenberg SA, Giannella-Neto D, Derendorf H, Rocha M, Bosco A et al (1998) Effect of fat distribution on the pharmacokinetics of cortisol in obesity. Int J Clin Pharmacol Ther 36:501-505

37. Roelfsema F, van Heemst D, Iranmanesh A, Takahashi P, Yang R et al (2017) Impact of age, sex and body mass index on cortisol secretion in 143 healthy adults. Endocr Connect 6:500-509

38. Esteban NV, Loughlin T, Yergey AL, Zawadzki JK, Booth JD et al (1991) Daily cortisol production rate in man determined by stable isotope dilution/mass spectrometry. J Clin Endocrinol Metab 72:39-45

39. Ragnarsson O, Mattsson AF, Monson JP, Filipsson Nyström H, Åkerblad AC et al (2014) The relationship between glucocorticoid replacement and quality of life in 2737 hypopituitary patients. Eur J Endocrinol 171:571-579

40. Hong AR, Ryu OH, Kim SY, Kim SW, Korean Adrenal Gland, and Endocrine Hypertension Study Group KrES (2017) Characteristics of Korean patients with primary adrenal insufficiency: a registry-based nationwide survey in Korea. Endocrinol Metab (Seoul) 32:466-474

41. Esposito D, Pasquali D, Johannsson G (2018) Primary adrenal insufficiency: managing mineralocorticoid replacement therapy. J Clin Endocrinol Metab 103:376-387

42. Werumeus Buning J, van Faassen M, Brummelman P, Dullaart RP, van den Berg G et al (2016) Effects of hydrocortisone on the regulation of blood pressure: results from a randomized controlled trial. J Clin Endocrinol Metab 101:3691-3699

Publisher's Note Springer Nature remains neutral with regard to jurisdictional claims in published maps and institutional affiliations. 